Once you have Acrobat Reader open on your computer, click on the Comment tab at the right of the toolbar:

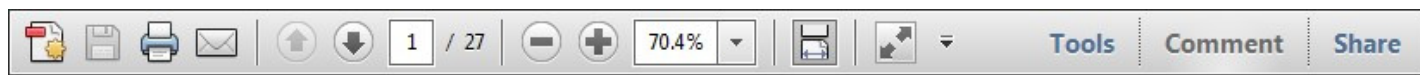

This will open up a panel down the right side of the document. The majority of tools you will use for annotating your proof will be in the Annotations section, pictured opposite. We've picked out some of these tools below:

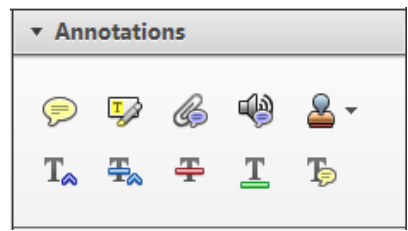

1. Replace (Ins) Tool - for replacing text.

Tistikes a line through text and opens up a text box where replacement text can be entered.

How to use it

- Highlight a word or sentence.

- Click on the Replace (Ins) icon in the Annotations section.

- Type the replacement text into the blue box that appears.

ıdard tramework for the analysis of $\mathrm{m}$ icy-Nevertheless, it also led to exog،

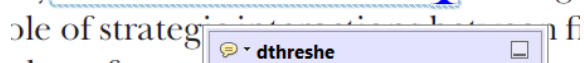
aber of comp 08/06/2011 15:58:17 $\quad$ O is that the $\mathrm{s} 1$, which led of nain compo: be level, are exc nc

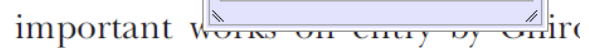
M heneforth) 1 we onen the 'hlarle $\mathrm{t}$

3. Add note to text Tool - for highlighting a section to be changed to bold or italic.

T) Highlights text in yellow and opens up a text box where comments can be entered.

How to use it

- Highlight the relevant section of text.

- Click on the Add note to text icon in the Annotations section.

- Type instruction on what should be changed regarding the text into the yellow box that appears.

namic responses of mark ups ent with the VAR evidence

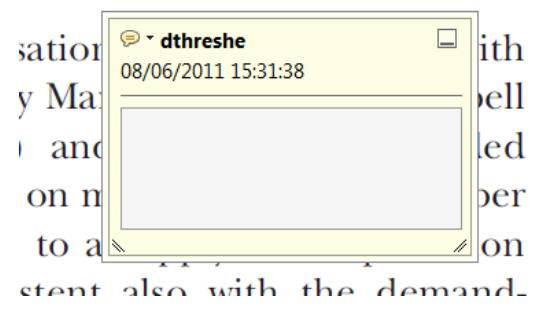

2. Strikethrough (Del) Tool - for deleting text.

T Strikes a red line through text that is to be deleted.

How to use it

- Highlight a word or sentence.

- Click on the Strikethrough (Del) icon in the Annotations section.

there is no room for extra protits al s ups are zero and the number of zet) values are not determined by Blanchard and Kiyotaki (1987), sfect competition in general equilil ts of aggregate demand and supply lassical framework assuming monol een on evorenous number of firme

4. Add sticky note Tool - for making notes at specific points in the text.

Marks a point in the proof where a comment needs to be highlighted.

How to use it

- Click on the Add sticky note icon in the Annotations section.

- Click at the point in the proof where the comment should be inserted.

- Type the comment into the yellow box that appears.

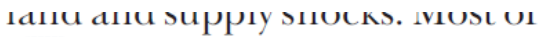

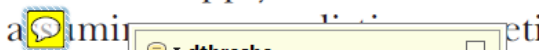

numbe $\mid \begin{aligned} & \ominus \text {-dthreshe } \\ & 08 / 06 / 2011 \text { 15:18:08 }\end{aligned}$

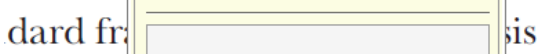

cy. Nev pa

le of st $\square$ wi

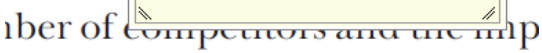

is that the structure of the secto 
5. Attach File Tool - for inserting large amounts of text or replacement figures.

Inserts an icon linking to the attached file in the appropriate place in the text.

\section{How to use it}

- Click on the Attach File icon in the Annotations section.

- Click on the proof to where you'd like the attached file to be linked.

- Select the file to be attached from your computer or network.

- Select the colour and type of icon that will appear in the proof. Click OK.

\section{E N D}

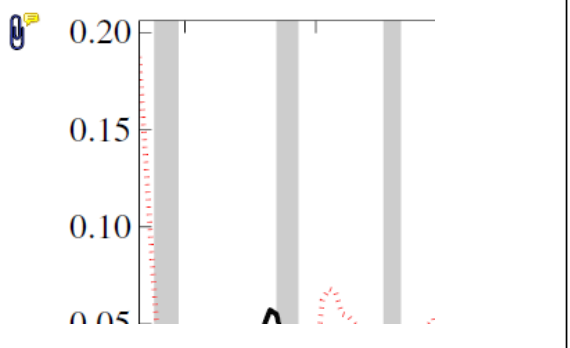

6. Drawing Markups Tools - for drawing shapes, lines and freeform annotations on proofs and commenting on these marks. Allows shapes, lines and freeform annotations to be drawn on proofs and for comment to be made on these marks.

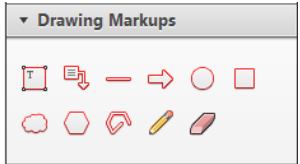

How to use it

- Click on one of the shapes in the Drawing Markups section.

- Click on the proof at the relevant point and draw the selected shape with the cursor.

- To add a comment to the drawn shape, move the cursor over the shape until an arrowhead appears.

- Double click on the shape and type any text in the red box that appears.

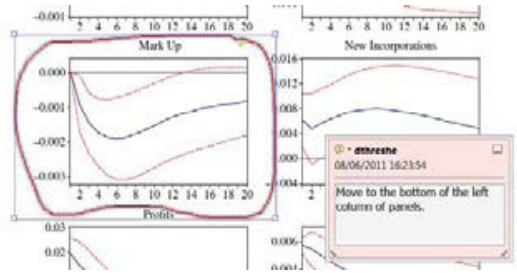




\begin{tabular}{|l|c|c|c|l|l|}
\hline \multirow{2}{*}{$\mathcal{U}$} & J N C & 13677 & \multirow{2}{*}{ WILEY } & Dispatch: 2.6.16 & CE: Menaka S \\
\cline { 2 - 3 } & Journal Code & Manuscript No. & & No. of pages: 12 & PE: Bhuvaneswari C \\
\hline
\end{tabular}

ORIGINAL ARTICLE

\title{
Estradiol-induced neurogenesis in the female accessory olfactory bulb is required for the learning of the male odor
}

\author{
1 Maïna Brus, Anne-Charlotte Trouillet, Vincent Hellier and Julie Bakker \\ Laboratory of Neuroendocrinology, Groupe Interdisciplinaire de Génoprotéomique Appliquée (GIGA) \\ Neurosciences, University of Liège, Liège, Belgium
}

\section{Abstract}

Odors processed by the main and accessory olfactory bulbs (MOB, AOB) are important for sexual behavior. Interestingly, both structures continue to receive new neurons during adulthood. A role for olfactory neurogenesis in sexual behavior in female mice has recently been shown and gonadal hormones such as estradiol can modulate adult neurogenesis. Therefore, we wanted to determine the role of estradiol in learning the odors of sexual partners and in the adult neurogenesis of female aromatase knockout mice (ArKO), unable to produce estradiol. Female wild-type (WT) and ArKO mice were exposed to male odors during 7 days, and olfactory preferences, cell proliferation, cell survival and functional involvement of newborn neurons were analyzed, using BrdU injections, in combination with a marker of cell activation (Zif268) and neuronal fate (doublecortin, neuronal nuclei,
\end{abstract}

marker of post-mitotic neurons). Behavioral tasks indicated that both WT and ArKO females were able to discriminate between the odors of two different males, but ArKO mice failed to learn the familiar male odor. Proliferation of newborn cells was reduced in ArKO mice only in the dentate gyrus of the hippocampus. Olfactory exposure decreased cell survival in the $A O B$ in WT females, suggesting a role for estradiol in a structure involved in sexual behavior. Finally, newborn neurons do not seem to be functionally involved in the $A O B$ of ArKO mice compared with WT, when females were exposed to the odor of a familiar male, suggesting that estradiol-induced neurogenesis in the $A O B$ is required for the learning of the male odor in female mice.

Keywords: aromatase knockout mice, cell proliferation, cell survival, functional integration, olfactory stimulation.

J. Neurochem. (2016) 10.1111/jnc. 13677
Many mammalian species use olfaction as the main sensory modality for the expression of behavior, including sexual behavior. Two sensory pathways are involved in processing olfactory cues in the brain. The main olfactory system has been primarily implicated in the processing of environmental odors, whereas the accessory olfactory system is thought to process odors associated with reproduction, including sexual behavior (Keller et al. 2009; Veyrac et al. 2011). Interestingly, both the main and the accessory olfactory bulbs (MOB and $\mathrm{AOB}$ ) continue to receive new olfactory neurons during adulthood, as has been shown for the dentate gyrus (DG) of the hippocampus (Ming and Song 2005; Lledo et al. 2006; Gheusi et al. 2013). Neurogenesis in the adult brain is characterized by three successive steps: cell proliferation, cell survival and functional integration of newborn cells into the neuronal network. In the olfactory system, newly born neurons originate from the subventricular zone (SVZ), where neural stem cells give rise to transient amplifying cells, which in turn differentiate into neuroblasts. These neuroblasts then migrate along the rostral migratory stream to reach the olfactory bulbs, where they differentiate into interneurons, and integrate the functional circuitry in both the MOB and the AOB. In the DG of the hippocampal formation, progenitor cells proliferate in the subgranular zone and give rise to neuroblasts that migrate over a short

Received September 17, 2015; revised manuscript received April 20, 2016; accepted May 12, 2016.

Address correspondence and reprint requests to Julie Bakker, University of Liège, Avenue Hippocrate 15, B36, 4000 Liège, Belgium. E-mail: jbakker@ulg.ac.be

Abbreviations used: $\mathrm{AOB}$, accessory olfactory bulb; ArKO, aromatase knockout mice; BrdU, bromo-2-deoxyuridine; C-C, clean-clean; DCX, doublecortin; DG, dentate gyrus; E2, estradiol; EB, estradiol benzoate; F-C, familiar-clean; F-F, familiar-familiar; F-U, familiar-unfamiliar; GCL, granule cell layer; GrCL, granular cell layer; ir, immunoreactive; 3 Jackson IR-E, Jackson ImmunoResearch Europe; Ki67, marker of cell proliferation; MOB, main olfactory bulb; NeuN, neuronal nuclei, marker of post-mitotic neurons; SVZ, subventricular zone; Zif268, immediate early gene used as a marker of activated cells. 
distance to reach the overlying granule cell layer where they become granule neurons (Abrous et al. 2005).

Olfactory neurogenesis could be regulated by a variety of endogenous and exogenous factors at all steps, allowing the olfactory system to adapt to any variation in the environment (Zhao et al. 2008). Indeed, recent studies have demonstrated that olfactory neurogenesis plays a role for female mice in the socio-sexual context. For instance, exposure to male urine increased the survival of granule cells in the AOB, MOB and DG of females (Mak et al. 2007; Oboti et al. 2011), whereas suppression of neurogenesis by an antimitotic agent disrupted mate recognition (Oboti et al. 2011) as well as the preference for a dominant male (Mak et al. 2007). In female mice, double immunohistochemistry labeling for c-Fos, a marker of cell activation, and bromo2-deoxyuridine (BrdU), a exogenous marker of cell division, showed that newborn granule cells in the AOB are activated by male odors during the second to third week of cell age and that integration of these newly born AOB cells occurred preferentially in the same circuits that responded to these socio-sexual stimuli (Oboti et al. 2011). Numerous studies have suggested the importance of olfactory neurogenesis in reproductive behavior, such as mate selection (Mak et al. 2007), pregnancy (Shingo et al. 2003), maternal recognition (Larsen et al. 2008; Larsen and Grattan 2010) and paternal recognition (Mak and Weiss 2010), all claiming to be mediated by prolactin. 1 pite its key role in reproductive behavior, however, littl ntion has been paid to a potential role for estradiol in modulating olfactory neurogenesis. Indeed, olfaction has been shown to be important for sexual behavior in female mice which is under direct control of estradiol (Bakker and Baum 2008; Bakker and Brock 2010). Furthermore, estradiol has been shown to modulate hippocampal and olfactory neurogenesis (Galea 2008; Brock et al. 2010). Depending on the experimental design, estradiol could either enhance or reduce cell proliferation and the survival of newborn cells in female rodents (Brock et al. 2010; Veyrac and Bakker 2011; Galea et al. 2013; McClure et al. 2013; Chan et al. 2014; Farinetti et al. 2015). The mapping of estradiol receptors in the mouse central nervous system revealed some scattered numbers of ER $\alpha$-ir cells in the granular layer of the olfactory bulbs, and depending on the study, none to moderate/strong numbers of ER $\beta$-ir cells were reported in this layer (Mitra et al. 2003; Merchenthaler et al. 2004). In the hippocampus, only a few weakly stained $\mathrm{ER} \alpha$ and ER $\beta$-ir cell nuclei were observed in the most ventral regions, including the $\mathrm{CA} 2-3$, the subiculum and the paraventriculum. Interestingly, the deep layer of the DG, where proliferating cells and neuronal progenitors are present (Merchenthaler et al. 2004), contained some intensely stained ER $\alpha$-ir cells that were not ER $\beta$-ir. The presence of ERs in neurogenic regions might suggest a direct effect of estradiol on the production of newborn neurons. Moreover, newborn olfactory neurons were not activated by male urinary odors in females carrying a targeted mutation in the aromatase gene (ArKO) and which are thus deficient in estradiol (Bakker et al. 2002a,b, 2003; Veyrac and Bakker 2011). This suggests an important role for estradiol in the functional integration of newborn olfactory cells in the context of reproductive behavior. Interestingly, ArKO female mice showed deficits in sexual behavior probably because of a reduced olfactory investigation of conspecifics (Bakker et al. 2002a; Pierman et al. 2006, 2008). Numerous studies have demonstrated that olfactory neurogenesis is involved in the memory processing of olfactory cues (Belnoue et al. 2011; Koehl and Abrous 2011; Lazarini and Lledo 2011; Gheusi et al. 2013). For instance, blocking neurogenesis impaired olfactory perceptual learning (Moreno et al. 2009) short- and long-term memory (Breton-Provencher et al. 2009; Lazarini et al. 2009; Sultan et al. 2010), whereas activating newborn olfactory neurons, by an optogenetic approach, enhanced discrimination learning and memory (Alonso et al. 2012). Therefore, in the present study, we wanted to determine the role of estradiol in the learning of odors of a potential sexual partner and in cell proliferation, cell survival and the functional involvement of newborn neurons in the adult $\mathrm{MOB}$ and $\mathrm{AOB}$ using female ArKO mice. Hippocampal neurogenesis was also characterized in ArKO females because gonadal hormones have been shown to induce plasticity in this brain area (Galea et al. 2013). Thus, we determined the role of estradiol in the production of newborn neurons and whether it would affect olfactory performances and mate preferences. Therefore, we exposed female wild-type (WT) and ArKO mice to male odors and analyzed cell proliferation (Experiment 1), cell survival (Experiment 2) and functional integration (Experiment 3). We used BrdU injections, in combination with an endogenous marker of cell activation (Zif268) and neuronal fate [doublecortin-(DCX), neuronal nuclei, marker of post-mitotic neurons $(\mathrm{NeuN})]$, to characterize the population of newborn olfactory neurons which might be involved in the learning of the odor of a sexual partner. Two olfactory behavioral tasks (habituation/dishabituation and olfactory preference tests) were used to investigate olfactory performances when provided with the choice of a familiar versus a non-familiar male partner.

\section{Materials and methods}

\section{Animals}

Aromatase knockout mice (ArKO) were generated by the disruption of exons 1 and 2 of the Cyp 19 gene (Honda et al. 1998). Heterozygous males and females for the ArKO mutation generated in our laboratory (CD1 strain) were further bred to generate WT and homozygous-null (ArKO) offspring. Mice were genotyped by PCR analysis of tail DNA (Bakker et al. 2002b). All breeding and genotyping were performed at the GIGA Neurosciences, University of Liège (Belgium). All experimental female mice (11-12 weeks old) were housed alone in filter-top cages 2 weeks before starting 
the experiments in climate-controlled housing units (12-h light-dark cycle). Food ('phytoestrogen-free' mouse chow D10001 AIN-76A, Brogaarden) and water were available ad libitum. All experiments were conducted in accordance with the guidelines set forth by the National Institutes of Health 'Guide for the Care and Used of Laboratory Animals', and were approved by the Ethical Committee for Animal Use of the University of Liège (protocol 234).

\section{Olfactory exposure}

All CD1 male stimuli (10-12 weeks old) used for this study were obtained from Janvier's lab (Le Genest St. Isle, France). Upon arrival, males were housed in standard individual cages. Females exposed to male soiled bedding were given daily fresh bedding $(25 \mathrm{~g})$ collected from the cages of 10 males (Experiments 1 and 2) or from one single male supplemented with $100 \mu \mathrm{L}$ of urine on filter paper (Experiment 3). Urines were collected from each CD1 male (familiar and unfamiliar) 1 week before starting the olfactory exposure, by holding the mouse by the scruff of the neck over an Eppendorf vial, taking care that no fecal contamination occurred. Urine samples coming from one single male were pooled and stored at $-20^{\circ} \mathrm{C}$ until use. In all experiments, females were exposed to male odors for 7 days. The control groups received clean bedding (Experiments 1 and 2) supplemented with $100 \mu \mathrm{L}$ of deionized water on filter paper (Experiment 3).

\section{BrdU treatments}

To identify newly generated cells at different survival times, mice received four injections intraperitonally (ip), $2 \mathrm{~h}$ apart, of bromo2-deoxyuridine (BrdU, Sigma-Aldrich, St. Louis, MO, USA) dissolved in $0.9 \% \mathrm{NaCL} / 0.007 \mathrm{M} \mathrm{NaOH}$, and administrated at $100 \mathrm{mg} / \mathrm{kg}$ body weight. Animals were killed $30 \mathrm{~min}$ after the last BrdU injection to study cell proliferation (Experiment 1), 4 weeks later to study neuronal survival (Experiment 2) or 3 weeks later to study the functional integration of newborn cells (Experiment 3 ).

\section{Experimental procedures}

A total of three different experiments and two behavioral tests were conducted. For each experiment, new groups of WT and ArKO mice were used. All animals were randomly assigned to the different experimental groups.

\section{Experiment 1: Role of estradiol in cell proliferation}

In order to analyze the role of estradiol in cell proliferation and neuroblasts population, WT ( $n=7-8$ per group) and ArKO $(n=8-9$ per group) female mice were exposed to male soiled bedding or to clean bedding to serve as controls for 7 days (Fig. 1a). Animals received four injections of $\mathrm{BrdU}$ on the last day of exposure (day 7) and were killed $30 \mathrm{~min}$ after the final injection. Cell proliferation was quantified in the SVZ and the DG of the hippocampus by counting the total number of BrdU-positive cells (BrdU+) in each structure. The number of immature neurons was quantified in the MOB, the AOB and the DG, by counting the total number of doublecortin-positive cells in granular cell layers (DCX+) (illustrations in Fig. 1b).

\section{Experiment 2: Role of estradiol in cell survival}

To determine the role of estradiol in cell survival, adult WT ( $n=7-$ 9 per group) and $\operatorname{ArKO}(n=7$ per group) female mice were
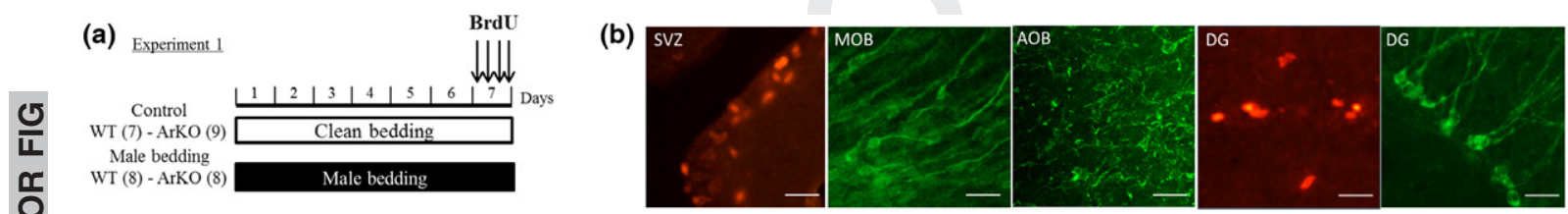

(c) $\quad$ Clean bedding Male bedding

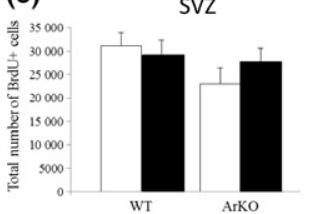

(h)

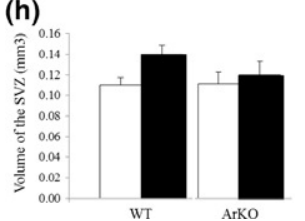

(d) $\mathrm{MOB}$

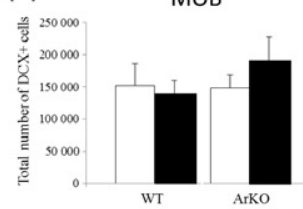

(i)

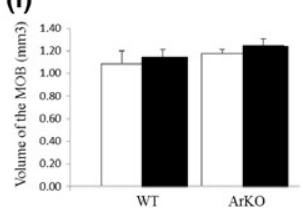

(e)

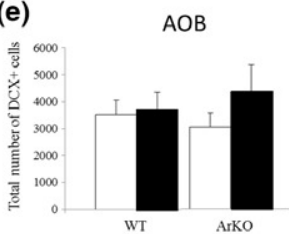

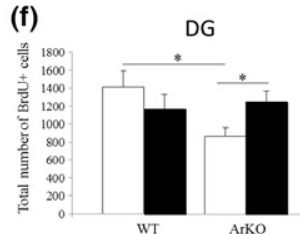

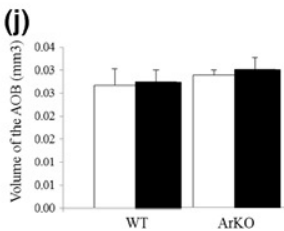

(k)

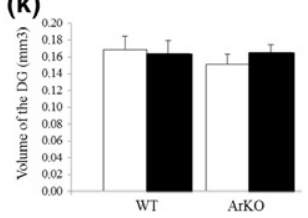

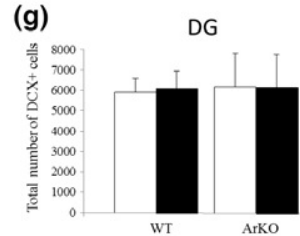

(I)

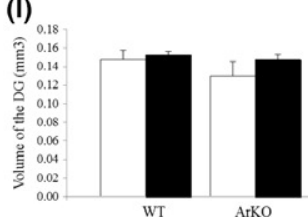

6 Fig. 1 Role of estradiol and impact of male odor exposure on cell proliferation and neuroblasts population in female mice. (a) Schematic representation of the protocol (Experiment 1). Control wild-type (WT) $(n=7-8)$ and ArKO $(n=8-9)$ mice were exposed to male bedding or clean bedding as control for 7 days. To quantify cell proliferation in the subventricular zone (SVZ) and in the dentate gyrus (DG), mice received four bromo-2-deoxyuridine (BrdU) injections (100 mg/kg, $2 \mathrm{~h}$ interval) on day 7. (b) Representative images showing fluorescent staining of $\mathrm{BrdU}+$ cells (red) and $\mathrm{DCX}+$ cells (green) in the $\mathrm{CV}$ the main olfactory bulb $(\mathrm{MOB})$, the accessory olfactory bulb (AOR the DG. (c) Total number of BrdU+ cells in the SVZ analyzed 30 min after last BrdU injection. ( $d$ and e) Total number of $D C X+$ cells in the MOB and the AOB. (f) Total number of BrdU+ cells in the DG.(g) Total number of $D C X+$ cells in the DG. Volumes of the SVZ (h), the MOB (i), the $A O B(j)$ and the $D G(k, l)$ in the experimental groups. Scale bars: $30 \mu \mathrm{m}$. 
exposed to male soiled bedding during 7 days or to clean bedding as control. On day 7, animals received four injections of BrdU and were killed 4 weeks later (Fig. 2a). Cell survival was estimated by quantification of BrdU+ cells in the MOB, the AOB and the DG (illustrations in Fig. 2b).

Experiment 3: Role of estradiol in the functional integration of newborn cells

Finally, we analyzed the role of estradiol in the functional integration of newborn cells by determining whether these cells were able to respond to socially relevant odors. WT $(n=7-8)$ and ArKO $(n=6-8)$ females were injected four times with BrdU, 2 weeks before being exposed to odors as it has previously been shown that newborn granule cells in the accessory olfactory system are specifically activated by male odors between 14 and 21 days of age (Oboti et al. 2011), as well as that olfactory stimulation recruited preferentially 2-week-old neurons (Belnoue et al. 2011). So, during the third week after receiving the BrdU injections, each female was exposed to the odors of one particular male (soiled bedding supplemented with $100 \mu \mathrm{L}$ of urine). At the end of the 7-day exposure, females were stimulated with the same male bedding supplemented with $100 \mu \mathrm{L}$ of urine ('Familiar-Familiar' group) or with bedding from a different male, supplemented with
$100 \mu \mathrm{L}$ of his urine ('Familiar-Unfamiliar' group) or with clean bedding supplemented with $100 \mu \mathrm{L}$ of deionized water ('FamiliarClean' group) to serve as controls. This protocol is based on the paper by Oboti et al. (2011). Ninety minutes after olfactory stimulation, females were killed and brains were processed for label immunohistochemistry for BrdU and Zif268 in the MOB the AOB. To measure basal levels of Zif268 in the MOB and the $\mathrm{AOB}$, an additional control group was used by exposing females to clean bedding in the third week after BrdU injections as well as to clean bedding for $90 \mathrm{~min}$ before being killed ('Clean-Clean' group) (Fig. 4a).

Finally, to determine that the observed effect of estradiol in the functional involvement of adult-born cells was not due to a decrease in the production of new cells, we analyzed cell proliferation and the survival of 3-week-old cells, by immunohistochemistry against BrdU and marker of cell proliferation (Ki67) (an endogenous marker of cell proliferation) in the MOB, the AOB, the SVZ and the DG.

\section{Olfactory discrimination task}

We used the habituation/dishabituation test to determine whether WT and ArKO mice were capable of discriminating between the odors of two different males coming from the same outbred strain (CD1). WT and ArKO females ( $n=6$ per group) were exposed to a
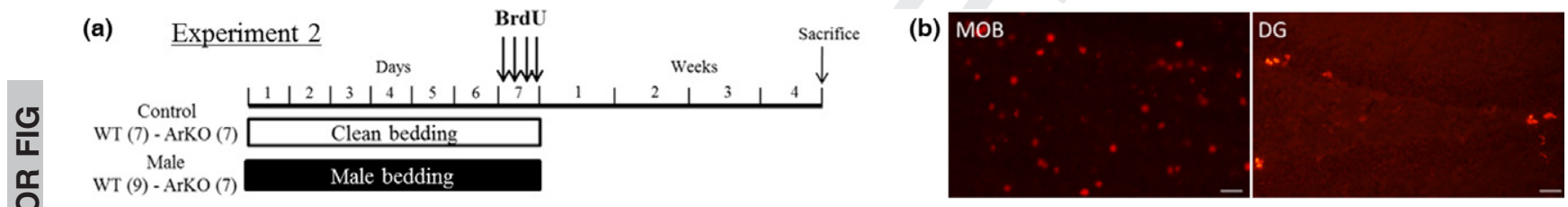

(c)
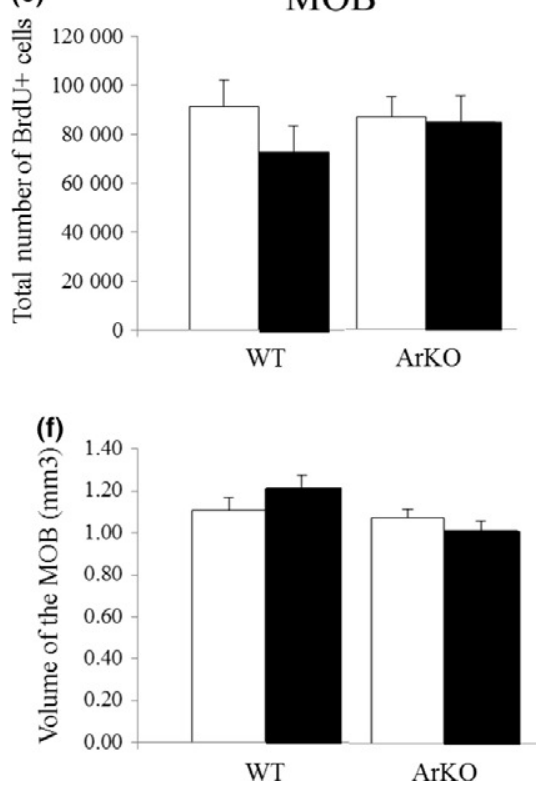

7 Fig. 2 Role of estradiol and impact of male odor exposure on cell survival in female mice. (a) Schematic representation of the protocol (Experiment 2). Wild-type (WT) $(n=7-9)$ and ArKO $(n=7)$ mice were exposed to male bedding or clean bedding as control, for 7 days. To quantify cell survival, mice received four bromo-2-deoxyuridine (BrdU) injections on day 7 (100 mg/kg, $2 \mathrm{~h}$ interval), and were killed 4 weeks (d)

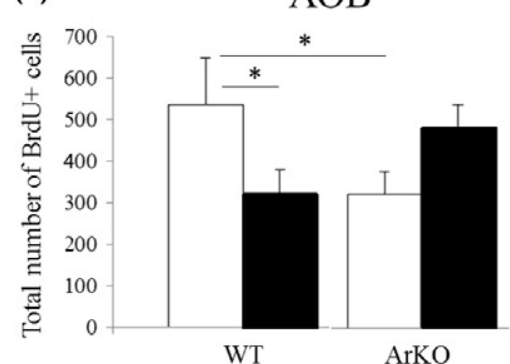

(g)

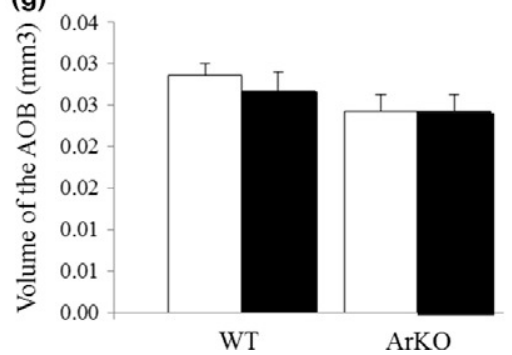

(e)

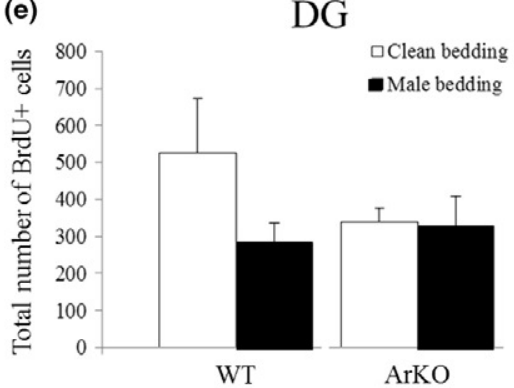

(h)

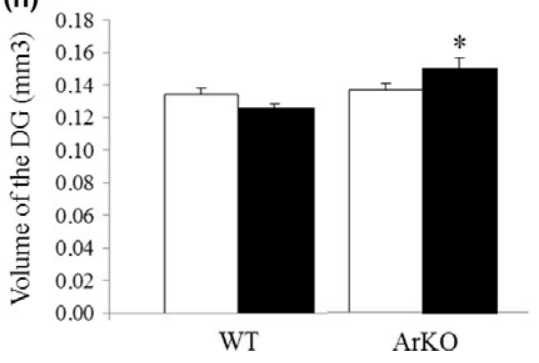

later. (b) Representative images showing BrdU+ cells fluorescent staining in the main olfactory bulb (MOB) and the dentate gyrus (DG). Total number of BrdU-positive cells in the MOB (c), the accessory olfactory bulb (AOB) (d) and the DG (e). Volumes of the MOB (f), the $A O B(g)$ and the DG $(h)$ in the experimental groups. Scale bars: $40 \mu \mathrm{m}$. 
sequence of successive odor presentations of male urine collected 4 from two CD1 males (No. 1 and No. 2) and one C57B16 male as control (Fig. 3a). Individual animal cages were taken from the housing unit and placed in a testing room illuminated by a dim yellow light. The stainless steel cage top containing their food and water was removed and replaced with a clean top. Odor stimuli were presented by pipetting $10 \mu \mathrm{L}$ of male urine (CD1 No- 1, CD1 No- 2 or C57B6) onto a piece of filter paper that was glued to a plastic weighing boat $(4.3 \times 4.3 \mathrm{~cm})$, which was then placed in the food hopper. The duration of investigation of the odor stimuli was recorded for $1 \mathrm{~min}$ using a stopwatch. Each urine was presented three times using fresh urine stimuli for each presentation. Any significant increase in olfactory investigation (dishabituation) when being exposed to a new odorant stimulus was considered as the subject detecting the odor.

Olfactory preference test

An odor preference test was used to determine whether the female had learned the odor of the male after being exposed to his bedding for 7 days. The same protocol of odor exposure was used as in Experiment 3 (Fig. 3c). On day 8, females were placed in the middle compartment of a three compartment box $(60 \times 13 \times 30 \mathrm{~cm})$. The compartments were separated by perforated opaque partitions, so that only odors were transmitted. Females were habituated to the test cage before testing. On the day of testing, familiar and unfamiliar male soiled bedding was placed randomly in either of the side compartments, supplemented with $100 \mu \mathrm{L}$ of urine on filter paper. A female was then placed into the middle compartment and was observed during $10 \mathrm{~min}$. The amount of time spent sniffing each side of the test cage was recorded.

\section{Immunohistochemistry}

All brain sections were processed for immunoreactivity as described in the supporting information. Briefly, immunostaining was carried out on $40-\mu \mathrm{m}$ sections using the following primary antibodies: rat anti-BrdU (1/500), goat anti-DCX (1/500), rabbit anti-Zif268 (1/500), mouse anti-NeuN (1/500) and rabbit anti-Ki67 (1/500). Primary antibodies were detected with donkey anti-rat $594\left(1 / 500_{\bar{\xi}}\right)$, donkey anti-mouse 488 (1/500) and donkey anti-goat 488 (1/500), or enhanced with donkey biotinylated anti-rabbit (1/1000), and conjugated with CY5-streptavidin (1/500) or a streptavidin AlexaFluor 488 (1/500).

\section{Quantification and image analysis}

\section{BrdU, DCX and Ki67 quantification}

All cell counts were conducted by an experimenter (M.B.) blind to the experimental condition of the animal. The total number of BrdU-, DCX- and Ki67-positive cells was counted with a stereological method (Glaser and Glaser 2000), using a Zeiss microscope coupled (a)

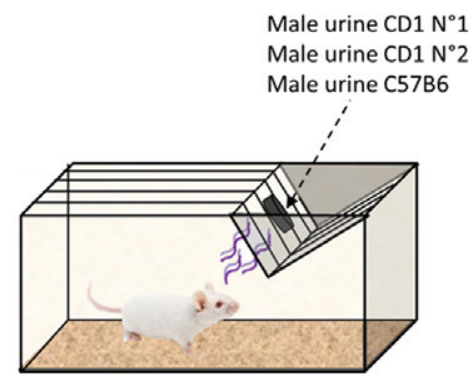

(b) (c)

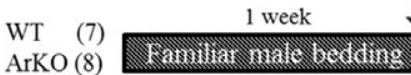

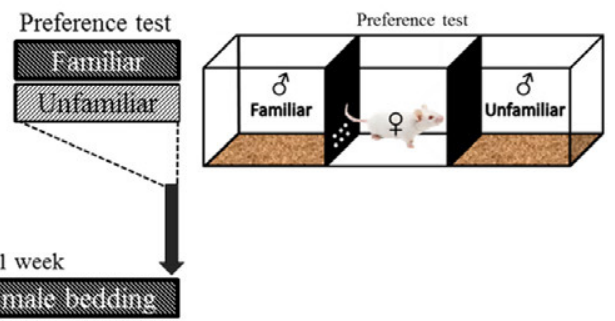

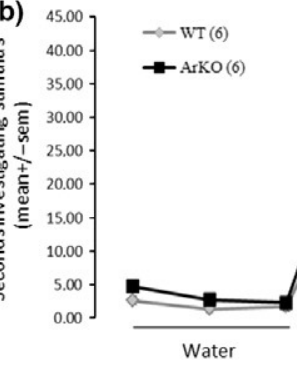

8 .

8 Fig. 3 Olfactory discrimination tasks in wild-type (WT) and ArKO female mice. (a) Schematic representation of the habituation/dishabituation olfactory test. WT and ArKO female mice were exposed to a sequence of successive odor presentations of male urines collected from two CD1 males ( $\mathrm{No}-1$ and $\mathrm{No}_{-2} 2$ ) and one C57B6 male. Each male urine was presented three times to the females by using fresh urine stimuli for each presentation. (b) Time spent by WT and ArKO females ( $n=6$ per group) investigating deionized water or urinary stimuli was recorded for each presentation (deionized water, male urine CD1 No. 1, male urine CD1 No. 2 and male urine C57B6). (c) Schematic representation of the olfactory preference
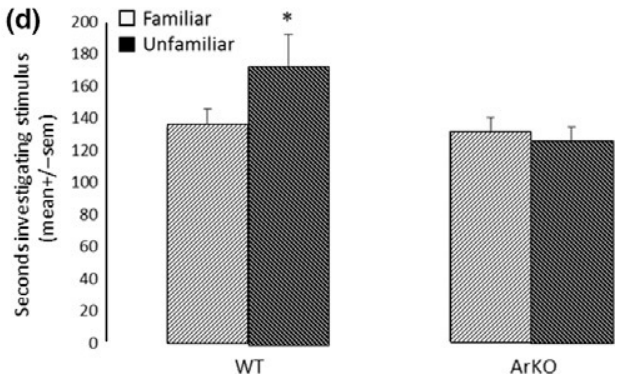

test. WT $(n=7)$ and ArKO $(n=8)$ mice were exposed to familiar male bedding during 1 week. The following day, mice were tested for olfactory preferences in a three-compartment box. Time spent sniffing one side of the test cage versus the other side was recorded, with familiar and unfamiliar male bedding being placed randomly in the lateral compartments. (d) Number of seconds investigating stimuli in WT and ArKO mice. ${ }^{* * *} p \leq 0.001$, $* * p \leq 0.01, * p \leq 0.05$ (Table S1). In the habituation/dishabituation test, post hoc comparisons were used between times spent investigating the third presentation of a particular stimulus and the first presentation of a subsequent stimulus. 
with mapping software (Mercator Pro, Explora Nova, La Rochelle, France), as described in the supplementary information.

\section{Zif268, Zif268/BrdU, BrdU/Zif268 and BrdU/NeuN quantification} To quantify the population of activated cells, serial sections from all mice in Experiment 3 were examined in the granular cell layer of the MOB (two sections) and the AOB (six sections). All sections were analyzed using the Olympus Fluoview FV1000 confocal system equipped with the Olympus IX81 inverted microscope (Olympus Europa, Hamburg, Germany), as described in the supplementary information.

\section{Statistical analysis}

Data were analyzed using parametric (two-way ANOVA, repeated measures ANOVA, $t$-test) or non-parametric tests (Kruskal-Wallis and Mann-Whitney) depending on data normality, as described in the supplementary information.

\section{Results}

Experiment 1: Role of estradiol in cell proliferation

Overall, cell proliferation and the number of immature neurons in the olfactory bulbs were not altered by estradiol deprivation as the number of BrdU- and DCX-positive cells was very similar in WT and ArKO mice in the SVZ (Fig. 1c), the MOB (Fig. 1d) and the AOB (Fig. 1e).

By contrast, a significant decrease in cell proliferation in the DG of ArKO mice was observed in clean condition compared with WT females (Fig. 1f). ANOVA showed a significant interaction between genotype and bedding exposure in the DG $(F=5.45, p=0.027)$. Post hoc analysis showed that the number of BrdU+ cells was significantly lower in ArKO mice compared with WT mice when exposed to clean bedding, representing basal levels of cell proliferation (WT clean vs. ArKO clean, $p=0.008$ ). However, the number of immature neurons (DCX+ cells) was not influenced by exposure to male odors in the DG (Fig. 1g, Table 1 1).

Volumes of the SVZ, the MOB, the AOB and the DG (Fig. 1h-l) were not affected by estradiol deprivation (see Table 1 1).

Experiment 1: Impact of exposure to male odors for 7 days on cell proliferation

Exposure to male odors did not seem to affect cell proliferation and the population of immature neurons in the olfactory system in either genotype (Fig. 1c, d and e). ANOvA showed no significant effects (see Table S1). Likewise, no differences were found in the anterior and the posterior part of the SVZ between WT and ArKO mice exposed to male

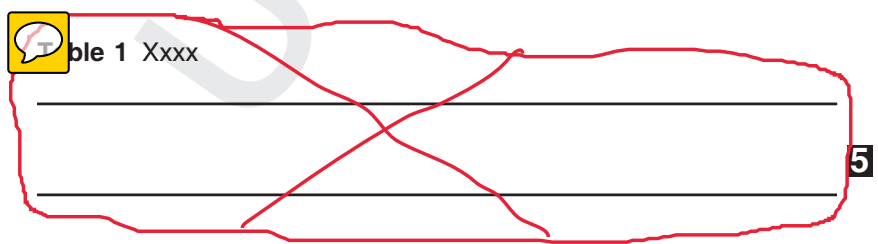

bedding (data not shown). By contrast, exposure to male bedding increased significantly the number of BrdU+ cells in the DG (Fig. 1f), but only in ArKO mice (ArKO clean bedding vs. ArKO male bedding: $p=0.048$ ). As observed in the olfactory system, the number of DCX + cells was not affected by exposure to male odors in the DG (Fig. 1g, Table S1). Volumes of the SVZ, the MOB, the AOB and the DG (Fig. 1h-1) were not affected by exposure to male odors (see Table 1 ).

Experiment 2: Role of estradiol in cell survival

Although cell proliferation was similar in the SVZ in both genotypes (Fig. 1c), cell survival appeared to be altered in ArKO females in the AOB, a structure mainly involved in sexual behavior (Fig. 2d). ANOvA showed a significant interaction between genotype and bedding exposure for the AOB $(F=6.57, p=0.016)$. Post hoc analyses showed that the total number of BrdU+ cells was significantly reduced in ArKO compared with WT females when exposed to clean bedding (WT clean vs. ArKO clean $p=0.046$ ). No differences between the two genotypes were observed in the MOB (Fig. 2c).

In the hippocampus, although cell proliferation was reduced in the DG of ArKO females (Fig. 1f), no such reduction was observed regarding the survival of newborn cells between WT and ArKO mice when exposed to either clean or male bedding (Fig. 2e).

Volumes of the MOB, the AOB and the DG were similar in both genotypes when exposed to clean bedding (Fig. 2f).

Experiment 2: Impact of exposure to male odors for 7 days on cell survival

In the olfactory system, exposure to male odors induced a significant decrease in the survival of newborn cells but only in WT females, as the number of BrdU+ cells was lower in the AOB of WT females, and no such difference was observed in ArKO mice (WT clean bedding vs. WT male bedding: $p=0.043$; ArKO clean bedding vs. ArKO male bedding: $p=0.15)$. No effect of bedding exposure was observed in the MOB irrespective of the genotype (Fig. 2c).

In the DG, the volume appeared to be slightly increased in ArKO mice exposed to male odors (Fig. 2h). ANOvA showed an interaction between genotype and bedding exposure $(F=6.01, p=0.02)$. Post hoc analyses showed that the volume of the DG was significantly greater in ArKO compared with WT females when exposed to male bedding (WT clean bedding vs. ArKO male bedding: $p=0.02$, WT male bedding vs. ArKO male bedding: $p=0.0004$, ArKO clean bedding vs. ArKO male bedding: $p=0.05$ ).

\section{Olfactory discrimination and olfactory preferences}

Both WT and ArKO females were able to discriminate between the odors of two different CD1 males, as the time spent sniffing each new odor at the first presentation was 
significantly higher than that of the previous odor in both genotypes (Fig. 3b). ANOVA showed an effect of odors $(F=15.51, \quad p<0.00001), \quad$ an effect of presentations $(F=51.08, p<0.00001)$ and an interaction between odors and presentations $(F=9.26, p<0.00001)$. Post hoc analyses showed that the first presentation of each odor was significantly more investigated than the previous odor (CD1 No. 1 vs. water $p=0.0001, \mathrm{CD} 1 \mathrm{No}-2$ vs. CD1 No$1 p=0.002$, C57B6 vs. CD1 No. $2 p=0.0001)$. Moreover, we observed that ArKO females did not present deficits in attractiveness to the odors, as investigation times of the first presentation of each odor stimulus did not significantly differ between the genotypes (Fig. 3b, Table S1).

In the olfactory preference test, WT females that had learned the familiar odor showed a preference for the unfamiliar male odor as they spent more time sniffing the unfamiliar male bedding compared with the familiar male bedding (Fig. 3d, $t=2.63, p=0.046$ ). By contrast, ArKO females did not show any preferences for the familiar or the unfamiliar male odor $(t=0.22, p=0.83)$.

Experiment 3: Role of estradiol in the functional involvement of newborn neurons

Finally, we determined the role of estradiol in the functional involvement of newly generated neurons by evaluating their expression of Zif268 in response to familiar and unfamiliar male odors in the MOB and the AOB. We observed that the basal expression of Zif268 was affected in ArKO mice, but only in the AOB (Fig. 4c and j), as the number of Zif268+ cells was significantly lower in ArKO compared with WT females. ANOVA showed a significant effect of genotype in the AOB $(F=8.28, p=0.006)$, but not in the MOB (Fig. $4 \mathrm{~b}, \mathrm{f}$; $F=0.54, p=0.46)$. Furthermore, the expression of Zif268 was lower in the MOB and the AOB of females exposed to and stimulated with clean bedding compared with females exposed to familiar bedding and stimulated with unfamiliar and clean bedding, irrespective of genotype (Fig. 4f, j, Table S1). Interestingly, no expression of Zif268 was observed in the DG of the hippocampus, suggesting that this structure was not activated by any of the olfactory stimulations in either WT or ArKO females.

In the MOB, similar levels of activated cells (Zif268+) were observed in WT and ArKO mice (Fig. 4f). ANOvA showed no effect of genotype, an effect of olfactory stimulation $(F=13.89, \quad p<0.0001)$, but no significant interaction between genotype and olfactory stimulation. By contrast, post hoc analyses showed that more cells were activated in both genotypes when exposed to a new odor, i.e., unfamiliar male bedding or clean bedding on the day of testing (Fig. 4f, Table S1). However, male odors activated differentially newborn cells in WT and ArKO mice, as the percentage of Zif268+/BrdU+ cells was higher in response to male odors in WT females (familiar and unfamiliar) compared with clean bedding, and no such difference was observed in ArKO females (Fig. 4g). ANOVA showed an effect of olfactory stimulation $(\mathrm{H}=9.09, p=0.028)$, and post hoc analyses showed that more newborn cells were activated when stimulated with familiar and unfamiliar male odors compared to clean bedding. In ArKO mice, no difference was found in females exposed to familiar male bedding and stimulated with familiar or unfamiliar male bedding or clean bedding, however a lower level of activated cells was observed in females exposed to clean bedding (see Table S1). Finally, the expression of Zif268 in BrdU-positive cells (BrdU+/ Zif268+) was similar in WT and ArKO females exposed to the familiar male bedding and stimulated with male odors (familiar and unfamiliar) or clean bedding (Fig. 4i). However, the percentage of BrdU/Zif268+ cells appeared to be lower in the MOB of females exposed to clean bedding compared with all other groups irrespective of the genotype (Fig. 4i). ANOvA showed an effect of olfactory stimulation $(F=21.72$, $p<0.00001)$ and post hoc analyses showed more BrdU+/ Zif268+ cells in females exposed to male odors during 1 week compared to clean bedding (see Table 1 ).

In the $\mathrm{AOB}$, we observed that the overall activation of cells was affected in ArKO mice, as the number of Zif268+ cells was lower in ArKO compared with WT females (Fig. 4j). ANOVA showed an effect of genotype $(F=8.28$, $p=0.006)$, and an effect of olfactory stimulation $(F=9.15$, $p=0.00006)$, but no interaction between genotype and olfactory stimulation $(F=0.55, p=0.65)$. As observed for the MOB, more cells were activated in the $\mathrm{AOB}$ in both ArKO and WT females when stimulated with the new odors, i.e., unfamiliar male bedding (tendency) and clean bedding (significant), compared to the familiar male odor in both genotypes (Fig. 4j, see Table S1). However, the proportion of newborn cells among the cells responding to the familiar male odor in the AOB was significantly different compared with the proportion of cells activated by the unfamiliar male odor or clean bedding, but only in WT females (Fig. 4k). ANOVA showed an effect of olfactory stimulation $(\mathrm{H}=11.99$, $p=0.007$ ), and post hoc analyses showed fewer activated newborn cells in the AOB when exposed to the familiar male odor (Fig. 4k, Table S1). Similar results were obtained by counting the percentage of BrdU+/Zif268+ cells. Indeed, the proportion of newborn cells activated by the familiar male odor was significantly lower compared with the proportion of cells that responded to clean bedding in WT females (Fig. $4 \mathrm{~m}, \mathrm{H}=12.56, p=0.006$, see Table 1 ). By contrast, no differences between the different odor stimulation groups were observed in ArKO mice and thus there was no effect of familiar odor male stimulation on the number of activated newborn cells, as ANOVA showed no effect of olfactory stimulation (Zif268+/BrdU+: $\mathrm{H}=0.56, \quad p=0.91 \quad$ and BrdU+/Zif268+: $\mathrm{H}=1.51, p=0.68)$.

Three weeks after BrdU injections, most of the BrdU+ cells in the granule cell layer of the MOB and the AOB expressed NeuN (Fig. 4h and 1), indicating that they were 
(a)

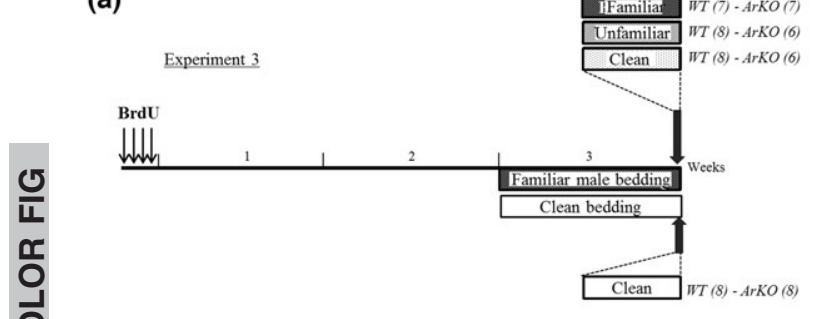

(b)

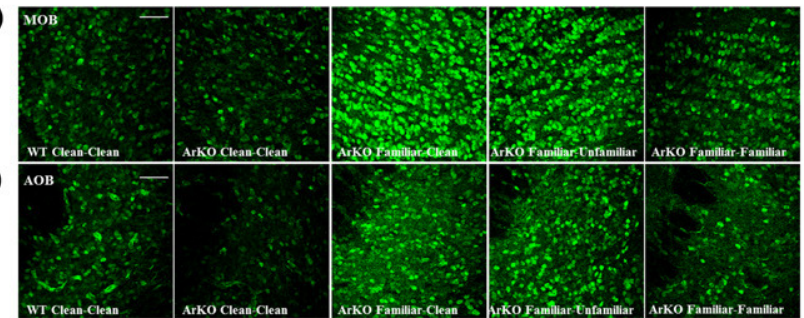

(d)

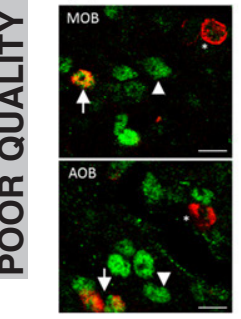

(e)

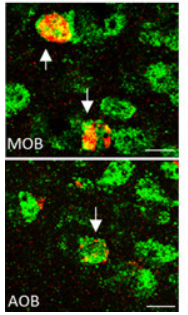

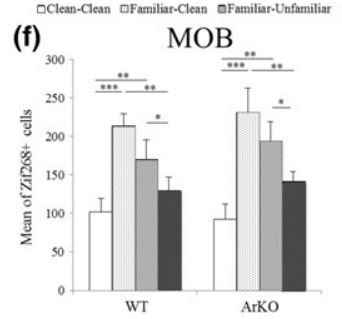

(h)

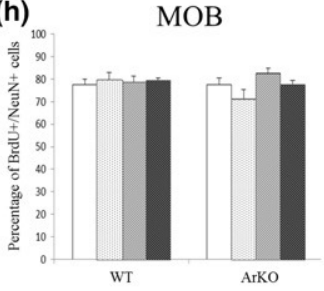

(g)

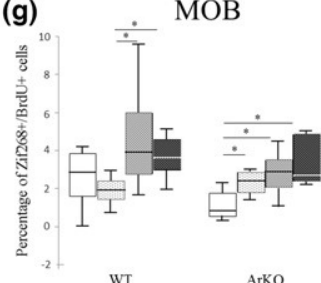

WT

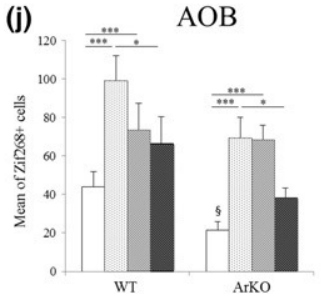

$\mathrm{AOB}$

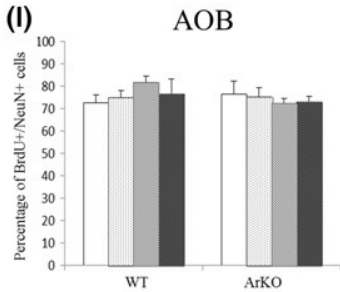

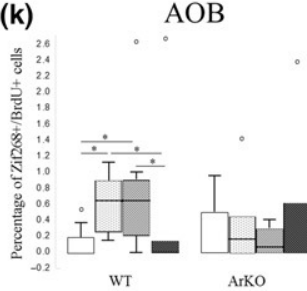

(m)

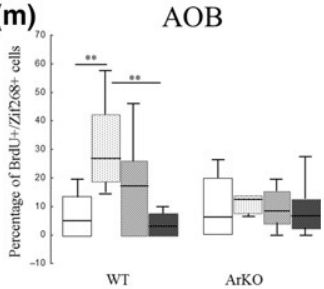

9 Fig. 4 Functional involvement of newborn cells in the main olfactory bulb (MOB) and the accessory olfactory bulb (AOB) after exposure to familiar male bedding. (a) Schematic representation of the protocol (Experiment 3). Wild-type (WT) $(n=23)$ and ArKO $(n=19)$ mice were exposed to familiar male bedding for 1 week. The day after, mice were separated into three subgroups and exposed during $1 \mathrm{~h} 30 \mathrm{~min}$ to the same familiar male bedding ('Familiar-Familiar' group), to an unfamiliar male bedding ('Familiar-Unfamiliar' group) or to clean bedding ('Familiar-Clean' group) as controls. Mice were killed at the end of the stimulation to assess immediate Zif268 early gene expression. To measure basal levels of Zif268, an additional control group was used. In this group, WT and ArKO females ( $n=8$ per group) were exposed to clean bedding on the third week and were stimulated with clean bedding during 90 min before killing ('Clean-Clean' group). To quantify the activation of newborn cells in each condition, all mice received four bromo-2-deoxyuridine (BrdU) injections $(100 \mathrm{mg} / \mathrm{kg}, 2 \mathrm{~h}$ interval) 2 weeks before exposure to the familiar male bedding. Representative confocal images of Zif268+ fluorescent staining observed in the MOB (b) and the AOB (c). (d) Representative confocal images of a Zif268+ (green)/BrdU+(red) double-labeled cell (arrow), a Zif268+/BrdU - cell (arrowhead) and a Zif268-/BrdU+ cell (asterisk) in the MOB and the $\mathrm{AOB}$, after exposure to the familiar male bedding ('Familiar-Familiar' group). (e) Representative confocal images of BrdU+/ nouronal nuclei, marker of post-mitotic nourons (NeuN) + cells (arrow) in the MOB and the AOB, 3 weeks after BrdU injections. (f) Number of Zif268+ cells in the MOB in the experimental groups. (g) Percentage of Zif268+/BrdU+ cells in the MOB. (h) Percentage of $\mathrm{BrdU}+/ \mathrm{NeuN}+$ cells in the MOB. (i) Percentage of $\mathrm{BrdU}+/ \mathrm{Zif268}+$ cells in the MOB. (j) Number of Zif268+cells in the AOB. (k) Percentage of Zif268+/BrdU+ cells in the AOB. (l) Percentage of BrdU $+/ \mathrm{NeuN}+$ cells in the AOB. (m) Percentage of $\mathrm{BrdU}+/ \mathrm{Zif268}+$ cells in the AOB. Values are expressed as mean \pm SEM (f, h, i, j and I) or as median and interquartile ranges $(\mathrm{g}, \mathrm{k}$ and $\mathrm{m}$ ) when data were not normally distributed and analyzed with non-parametric tests (Kruskal-Wallis and Mann-Whitney tests). Scale bars: $50 \mu \mathrm{m}$ (b and c); $10 \mu \mathrm{m}(\mathrm{d}-\mathrm{e})$. o: extreme values.

could be because of a deficit in the quantity of newborn cells generated in these mice or to an increased neurogenesis in WT mice in response to being exposed to male bedding for 7 days. Therefore, to determine whether exposure to familiar male bedding affects adult neurogenesis, we estimated cell proliferation and cell survival of newly born cells in Experiment 3 by also counting the number of BrdU+ cells and Ki67+ cells (Fig. 5a and b). Interestingly, our results in ArKO mice seemed to be specific to functional integration, as 
(a)

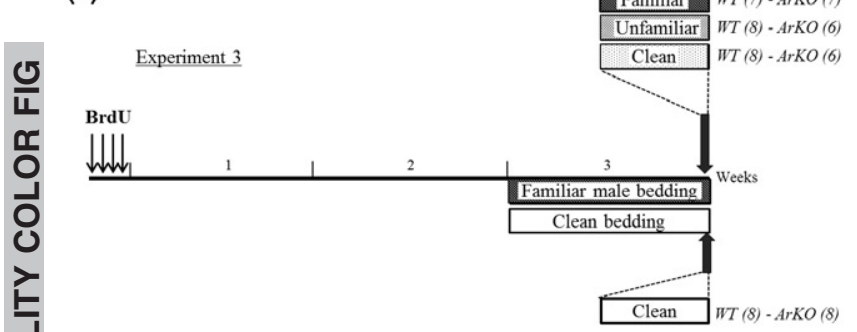

(b)

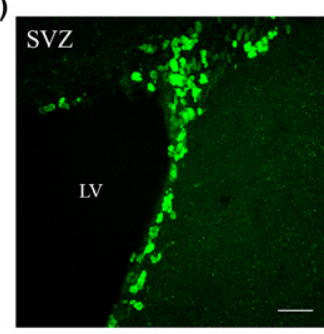

(d)

(c)

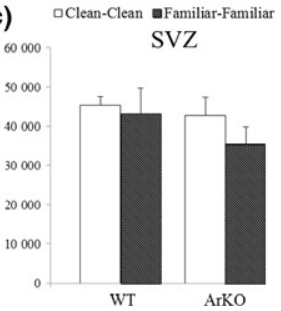

(e)

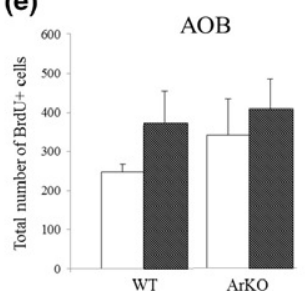

(f)

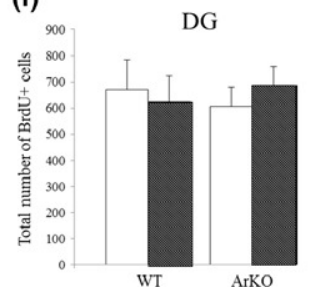

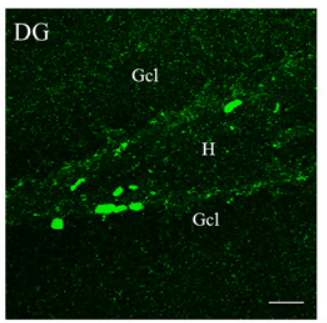

(g)

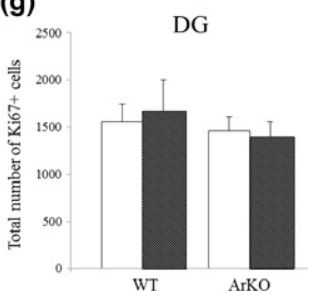

10 Fig. 5 Effect of familiar male odors exposure on basal adult neurogenesis in the main olfactory bulb (MOB), the accessory olfactory bulb $(A O B)$ and the dentate gyrus (DG). (a) Schematic representation of the protocol (Experiment 3). To determine whether estradiol affects basal neurogenesis, we estimated cell proliferation and cell survival of 3-week newly born cells in wild-type (WT) and ArKO mice.

neither estradiol nor exposure to male odors affected adult olfactory neurogenesis. Indeed, ANOva showed no effect of genotype or olfactory exposure on the number of BrdU+ and $\mathrm{Ki} 67+$ cells in the SVZ, the MOB, the AOB and the DG, both in WT and ArKO mice (Fig. 5c-g).

\section{Discussion}

Three main results have been obtained in this study. First, the proliferation of newborn cells is reduced in ArKO mice but only in the DG of the hippocampus when newborn cells were labeled with BrdU, suggesting that this structure is sensitive to variations in estradiol, specifically before DNA synthesis (Experiment 1). Second, a role for estradiol in cell survival was observed but only in the AOB, which is mainly involved in sexual behavior (Experiment 2). Finally, estradiol seems to be important for the functional involvement of newborn olfactory cells in the AOB, when females are learning the odor of a familiar male, without affecting basal adult olfactory neurogenesis (Experiment 3). These results might thus open new insights into the role of adult neurogenesis in the olfactory processing of socio-sexual cues regulated by estrogens.

The role of estradiol in cell proliferation only in the DG of the hippocampus

In the present study, we found no clear evidence for a role of estradiol in cell proliferation in the olfactory system as no differences were observed in the number of proliferating cells

(b) Representative confocal images showing newly dividing marker of cell proliferation (Ki67)+ cells (green) in the subventricular zone (SVZ) and the DG. Total numbers of Ki67+ cells (cell proliferation) in the SVZ (c) and the DG (g), and total numbers of bromo-2deoxyuridine (BrdU)+ cells (cell survival) in the MOB (d), the AOB (e) and the DG (f). Scale bars: $40 \mu \mathrm{m}$.

between ArKO and WT mice, thereby corroborating previous results (Veyrac and Bakker 2011). Similarly, 7-day exposure to the odors of males seemed to have no effect on the production of olfactory newborn cells for either genotype. However, we report here for the first time a reduced proliferation of progenitor cells, labeled with BrdU, in the DG of ArKO females. Numerous studies have demonstrated a rather inconsistent role of estradiol in cell proliferation in the DG (either positive, negative or no effect), depending on the experimental design (acute or chronic administration), type of estrogens (17- $\beta$-E2, EB, or 17- $\alpha$-E2) and species (rat, mice, prairie voles) (Tanapat et al. 1999; Galea et al. 2008, 2013; Pawluski et al. 2009). As we observed an effect of estradiol deficiency only in the DG, we propose that estradiol differentially controls cell proliferation in the olfactory system versus the hippocampus. Moreover, the reduction in cell proliferation observed in ArKO females was inversed by a 7-day exposure to the odors of males, indicating that this structure remains highly plastic in response to estradiol. Furthermore, estradiol might affect the cell cycle of progenitor cells in the DG, as the decrease in cell proliferation in the DG is only observed in ArKO mice when cells were labeled with the BrdU marker, and no such decrease was observed when proliferating cells were labeled with Ki67, an endogenous marker. This discrepancy might be explained by differences in the population of cells observed. BrdU+ cells represent only the part of dividing cells which have incorporated the BrdU marker during the $\mathrm{S}$ phase of cell division, whereas the Ki67 marker is expressed by cells 
during all active phases of the cell cycle, allowing us to observe a larger population of proliferating cells (Kee et al. 2007). Taken together, these results suggest that females unable to produce estradiol could present a slowdown in the cell cycle just before DNA synthesis, leading to a significant reduction in the number of newborn hippocampal cells in the $\mathrm{S}$ phase (BrdU+ cells).

Finally, while cell proliferation was reduced in ArKO mice, we observed that cell survival in the DG was not significantly affected in these females. These results indicate that estradiol might specifically affect the first step of adult neurogenesis (cell proliferation) without influencing the number of newborn neurons in the DG 4 weeks later (cell survival).

Role of estradiol in cell survival in the $A O B$

In the present study, we analyzed the role of estradiol in the survival of newborn cells, measured 4 weeks after exposure to male odors. A reduced number of surviving cells was observed in the AOB, but not the MOB, after 7 days of exposure to male soiled bedding. By contrast, a previous study (Mak et al. 2007) has found that 7-day exposure to male odors increased both cell proliferation and the production of new neurons in the adult female olfactory bulbs and DG. This discrepancy could be explained by major differences in the protocol regarding olfactory exposure. Indeed, in the study by Mak et al. (2007), to expose mice to male pheromones, females were placed in groups of three in a cage containing male odors for 2 days. This sequence was then repeated every 2 days to complete the 7-day exposure. In our study, females were isolated before the experiment and then exposed daily to fresh male soiled bedding, to avoid any confounding effects induced by the change in environment and social interaction between the females. The reduced number of newborn neurons observed in the AOB suggests that olfactory cues relevant for sexual behavior downregulate neurogenesis only in a structure of which it has been proposed to be important for the processing of odors implicated in sexual behavior. This active elimination process of newborn neurons could optimize olfaction by playing a crucial role in optimal odorant exploration, discrimination and olfactory learning (Mouret et al. 2008, 2009). Interestingly, no such difference between the two olfactory conditions was observed in both the AOB and MOB in ArKO mice, presumably because of their estradiol deficiency. However, a significant reduction in cell survival was observed in the AOB of ArKO mice compared to WT in the control condition, suggesting that while cell proliferation might not be modulated by estradiol, cell survival appears to be affected, as was previously shown (Veyrac and Bakker 2011). Thus, there might be a physiological role of estradiol in the neuronal elimination of newborn cells that will or will not survive during this critical period of 4 weeks postinjection. However, this reduction was not observed in
Experiment 3 when cell survival was evaluated at 3 weeks after BrdU injections, suggesting that estradiol might have a differential effect on cell survival in the AOB depending on the age of the cells. Although the present experiment cannot rule out a possible effect of prolactin, this possibility is unlikely in light of a previous study reporting elevated prolactin levels in adult ArKO mice (McPherson et al. 2001). Indeed, as estradiol could have a stimulatory effect on prolactin secretion (Horiguchi et al. 2007; Saitoh et al. 2010; Avtanski et al. 2014), WT females could have higher levels of circulating prolactin than ArKO females. It has been shown that prolactin could enhance neurogenesis in the adult female brain (Shingo et al. 2003). Therefore, the higher survival of newborn cells in the AOB of WT compared to ArKO females could be a consequence of higher prolactin levels in WT mice. However, no data are available concerning levels of prolactin in ArKO females and only one study reported elevated, rather than decreased, levels of prolactin in adult male ArKO mice (McPherson et al. 2001).

\section{The role of estradiol in the functional involvement of} newborn cells

We analyzed the expression of Zif268 in BrdU-positive granular neurons in the MOB and the AOB of WT and ArKO females (Zif268+/BrdU+ and BrdU+/Zif268+). After 7-day exposure to familiar male bedding, we observed that olfactory stimulation using two new odors (i.e. unfamiliar male bedding or clean bedding) increased the number of Zif268-positive cells in the MOB and the AOB in both genotypes, compared to the familiar male odors, suggesting that females with or without estradiol were able to discriminate between the different odors. The habituation/dishabituation task confirmed these results, as both WT and ArKO females were able to discriminate between the odors of two males coming from the same strain. However, the percentage of newly born cells activated by odors of familiar and unfamiliar males only increased in WT females (Zif268+/BrdU+ cells), suggesting that newborn neurons are recruited in the MOB to process odors of males but do not participate directly in the learning of the familiar male odor. The percentage of BrdU+/Zif268+ cells was similar in the MOB of WT and ArKO females stimulated with either clean bedding, unfamiliar or familiar male bedding for 7 days. Taken together, these results suggest that the observed changes in odor processing in ArKO mice (Zif268+ cells) do not specifically rely on changes in the involvement of newborn neurons, but rather on changes in the entire MOB network. Interestingly, WT females presented a specific activation of newborn cells in response to the familiar male odor in the AOB compared to the unfamiliar male odor or clean bedding (Zif268+/BrdU+ and BrdU+/Zif268+ cells). These results suggest that a specific population of neurons might be implicated in learning the odor of the familiar male, including a weak quantity of newborn accessory olfactory neurons. No difference was, however, observed in ArKO 
females between each odor (familiar male, unfamiliar male and clean bedding), suggesting a deficit in the integration of newborn neurons in the AOB in these females.

These results not only reinforce previous data on the modulating role of estradiol in adult neurogenesis and the integration of newborn cells (Brock et al. 2010; Veyrac and Bakker 2011), but may also explain the disturbed phenotype of ArKO female mice. Indeed, ArKO females present strong deficits in both olfactory investigation of sociosexual cues and reproductive behavior (Bakker et al. 2002a; Pierman et al. 2006). In the present study, we showed that ArKO mice are able to discriminate between the different male odors, but that they presented deficits in the learning of the familiar male odor and in the functional involvement of newborn cells. We suggest that estradiol deficiency does not induce a dramatic deficit at the sensory level, but might interfere specifically with $\mathrm{AOB}$ neurogenesis by altering the recruitment of newborn olfactory neurons in response to reproductively relevant odors, leading to behavioral deficits in mate preferences and sexual behavior.

Further experiments are required to better understand the role of estradiol exposure during the postnatal period and its influence on early neurogenesis which could play an important role in shaping the architecture of the AOB, thereby allowing neurons generated later in life to optimally survive and to be functionally integrated into the adult network. Previous work has shown that there is a critical prepubertal period during which estradiol seems to have feminizing effects on the brain (Brock et al. 2011), i.e., administration of estradiol between P15 and P25 restored lordosis behavior and male-directed mate preferences in ArKO females. It might be postulated that during the prepubertal period estradiol is needed to organize the olfactory network, as newborn neurons are integrated into the network to learn the odors of the male.

\section{Acknowledgments and conflict of interest disclosure}

The authors would like to thank Drs Desroziers-Crossard, Taziaux and Brock for their technical help. This work was supported by a grant from the Fonds National de la Recherche Scientifique (F.R.S.FNRS; 1.5.033.12) and with support from the French Community Wallonie-Brussels and the National Lotery (FNRS 2.4572.09). Julie Bakker is a Senior Research Associate of the FNRS. The authors have no conflicts of interest to declare.

All experiments were conducted in compliance with the ARRIVE guidelines.

\section{Supporting information}

Additional Supporting Information may be found online in the supporting information tab for this article:

Table S1. Results of all statistical analyses performed.

\section{References}

Abrous D. N., Koehl M. and Le Moal M. (2005) Adult neurogenesis: from precursors to network and physiology. Physiol. Rev. 85, 523569.

Alonso M., Lepousez G., Sebastien W., Bardy C., Gabellec M. M., Torquet N. and Lledo P. M. (2012) Activation of adult-born neurons facilitates learning and memory. Nat. Neurosci. 15, 897904.

Avtanski D., Novaira H. J., Wu S., Romero C. J., Kineman R., Luque R. M., Wondisford F. and Radovick S. (2014) Both estrogen receptor alpha and beta stimulate pituitary GH gene expression. Mol. Endocrinol. (Baltimore, Md.), 28, 40-52.

Bakker J. and Baum M. J. (2008) Role for estradiol in female-typical brain and behavioral sexual differentiation. Front. Neuroendocrinol. 29, 1-16.

Bakker J. and Brock O. (2010) Early oestrogens in shaping reproductive networks: evidence for a potential organisational role of oestradiol in female brain development. J. Neuroendocrinol. 22, 728-735.

Bakker J., Honda S., Harada N. and Balthazart J. (2002a) The aromatase knock-out mouse provides new evidence that estradiol is required during development in the female for the expression of sociosexual behaviors in adulthood. J. Neurosci. 22, 9104-9112.

Bakker J., Honda S., Harada N. and Balthazart J. (2002b) Sexual partner preference requires a functional aromatase (cyp19) gene in male mice. Horm. Behav. 42, 158-171.

Bakker J., Honda S., Harada N. and Balthazart J. (2003) The aromatase knockout (ArKO) mouse provides new evidence that estrogens are required for the development of the female brain. Ann. N. Y. Acad. Sci. 1007, 251-262.

Belnoue L., Grosjean N., Abrous D. N. and Koehl M. (2011) A critical time window for the recruitment of bulbar newborn neurons by olfactory discrimination learning. J. Neurosci. 31, 1010-1016.

Breton-Provencher V., Lemasson M., Peralta M. R., 3rd and Saghatelyan A. (2009) Interneurons produced in adulthood are required for the normal functioning of the olfactory bulb network and for the execution of selected olfactory behaviors. J. Neurosci. 29, 15245 15257.

Brock O., Keller M., Veyrac A., Douhard Q. and Bakker J. (2010) Short term treatment with estradiol decreases the rate of newly generated cells in the subventricular zone and main olfactory bulb of adult female mice. Neuroscience 166, 368-376.

Brock O., Baum M. J. and Bakker J. (2011) The development of female sexual behavior requires prepubertal estradiol. J. Neurosci. 31, 5574-5578.

Brus M., Keller M. and Levy F. (2013) Temporal features of adult neurogenesis: differences and similarities across mammalian species. Front Neurosci. 7, 135.

Chan M., Chow C., Hamson D. K., Lieblich S. E. and Galea L. A. (2014) Effects of chronic oestradiol, progesterone and medroxyprogesterone acetate on hippocampal neurogenesis and adrenal mass in adult female rats. J. Neuroendocrinol. 26, 386399.

Farinetti A., Tomasi S., Foglio B., Ferraris A., Ponti G., Gotti S., Peretto P. and Panzica G. C. (2015) Testosterone and estradiol differentially affect cell proliferation in the subventricular zone of young adult gonadectomized male and female rats. Neuroscience 286, 162-170.

Galea L. A. (2008) Gonadal hormone modulation of neurogenesis in the dentate gyrus of adult male and female rodents. Brain Res. Rev. 57, 332-341.

Galea L. A., Uban K. A., Epp J. R., Brummelte S., Barha C. K., Wilson W. L., Lieblich S. E. and Pawluski J. L. (2008) Endocrine regulation of cognition and neuroplasticity: our pursuit to unveil 
the complex interaction between hormones, the brain, and behaviour. Can. J. Exp. Psychol. 62, 247-260.

Galea L. A., Wainwright S. R., Roes M. M., Duarte-Guterman P., Chow C. and Hamson D. K. (2013) Sex, hormones and neurogenesis in the hippocampus: hormonal modulation of neurogenesis and potential functional implications. J. Neuroendocrinol. 25, 10391061.

Gheusi G., Lepousez G. and Lledo P. M. (2013) Adult-born neurons in the olfactory bulb: integration and functional consequences. Curr. Top. Behav. Neurosci. 15, 49-72.

Glaser J. R. and Glaser E. M. (2000) Stereology, morphometry, and mapping: the whole is greater than the sum of its parts. J. Chem. Neuroanat. 20, 115-126.

Honda S., Harada N., Ito S., Takagi Y. and Maeda S. (1998) Disruption of sexual behavior in male aromatase-deficient mice lacking exons 1 and 2 of the cyp19 gene. Biochem. Biophys. Res. Commun. 252, 445-449.

Horiguchi K., Fukuta S., Yoshida M., Kosugi T., Naito J., Ishida M. and Harigaya T. (2007) Estrogen regulates the serum level of phosphorylated prolactin in mice. J. Reprod. Dev. 53, 915-922.

Kee N., Teixeira C. M., Wang A. H. and Frankland P. W. (2007) Preferential incorporation of adult-generated granule cells into spatial memory networks in the dentate gyrus. Nat. Neurosci. 10, 355-362.

Keller M., Baum M. J., Brock O., Brennan P. A. and Bakker J. (2009) The main and the accessory olfactory systems interact in the control of mate recognition and sexual behavior. Behav. Brain Res. 200, 268-276.

Koehl M. and Abrous D. N. (2011) A new chapter in the field of memory: adult hippocampal neurogenesis. Eur. J. Neuorsci. 33, $1101-1114$.

Larsen C. M. and Grattan D. R. (2010) Prolactin-induced mitogenesis in the subventricular zone of the maternal brain during early pregnancy is essential for normal postpartum behavioral responses in the mother. Endocrinology 151, 3805-3814.

Larsen C. M., Kokay I. C. and Grattan D. R. (2008) Male pheromones initiate prolactin-induced neurogenesis and advance maternal behavior in female mice. Horm. Behav. 53, 509-517.

Lazarini F. and Lledo P. M. (2011) Is adult neurogenesis essential for olfaction? Trends Neurosci. 34, 20-30.

Lazarini F., Mouthon M. A., Gheusi G., de Chaumont F., Olivo-Marin J. C., Lamarque S., Abrous D. N., Boussin F. D. and Lledo P. M. (2009) Cellular and behavioral effects of cranial irradiation of the subventricular zone in adult mice. PLoS ONE 4, e7017.

Lledo P. M., Alonso M. and Grubb M. S. (2006) Adult neurogenesis and functional plasticity in neuronal circuits. Nat. Rev. Neurosci. 7, 179-193.

Mak G. K. and Weiss S. (2010) Paternal recognition of adult offspring mediated by newly generated CNS neurons. Nat. Neurosci. 13, 753-758.

Mak G. K., Enwere E. K., Gregg C., Pakarainen T., Poutanen M., Huhtaniemi I. and Weiss S. (2007) Male pheromone-stimulated neurogenesis in the adult female brain: possible role in mating behavior. Nat. Neurosci. 10, 1003-1011.

McClure R. E., Barha C. K. and Galea L. A. (2013) 17beta-Estradiol, but not estrone, increases the survival and activation of new neurons in the hippocampus in response to spatial memory in adult female rats. Horm. Behav. 63, 144-157.

McPherson S. J., Wang H., Jones M. E., Pedersen J., Iismaa T. P., Wreford N., Simpson E. R. and Risbridger G. P. (2001) Elevated androgens and prolactin in aromatase-deficient mice cause enlargement, but not malignancy, of the prostate gland. Endocrinology 142, 2458-2467.
Merchenthaler I., Lane M. V., Numan S. and Dellovade T. L. (2004) Distribution of estrogen receptor alpha and beta in the mouse central nervous system: in vivo autoradiographic and immunocytochemical analyses. J. Comp. Neurol. 473, 270-291.

Ming G. L. and Song H. (2005) Adult neurogenesis in the mammalian central nervous system. Аnnи. Rev. Neurosci. 28, 223-250.

Mitra S. W., Hoskin E., Yudkovitz J. et al. (2003) Immunolocalization of estrogen receptor beta in the mouse brain: comparison with estrogen receptor alpha. Endocrinology 144, 2055-2067.

Moreno M. M., Linster C., Escanilla O., Sacquet J., Didier A. and Mandairon N. (2009) Olfactory perceptual learning requires adult neurogenesis. Proc. Natl Acad. Sci. USA 106, 17980-17985.

Mouret A., Gheusi G., Gabellec M. M., de Chaumont F., Olivo-Marin J. C. and Lledo P. M. (2008) Learning and survival of newly generated neurons: when time matters. J. Neurosci. 28, 1151111516.

Mouret A., Lepousez G., Gras J., Gabellec M. M. and Lledo P. M. (2009) Turnover of newborn olfactory bulb neurons optimizes olfaction. J. Neurosci. 29, 12302-12314.

Oboti L., Schellino R., Giachino C., Chamero P., Pyrski M., LeindersZufall T., Zufall F., Fasolo A. and Peretto P. (2011) Newborn interneurons in the accessory olfactory bulb promote mate recognition in female mice. Frontiers Neurosci. 5, 113.

Pawluski J. L., Brummelte S., Barha C. K., Crozier T. M. and Galea L. A. (2009) Effects of steroid hormones on neurogenesis in the hippocampus of the adult female rodent during the estrous cycle, pregnancy, lactation and aging. Front. Neuroendocrinol. 30, 343357.

Petreanu L. and Alvarez-Buylla A. (2002) Maturation and death of adultborn olfactory bulb granule neurons: role of olfaction. J. Neurosci. 22, 6106-6113.

Pierman S., Douhard Q., Balthazart J., Baum M. J. and Bakker J. (2006) Attraction thresholds and sex discrimination of urinary odorants in male and female aromatase knockout (ArKO) mice. Horm. Behav. 49, 96-104.

Pierman S., Douhard Q. and Bakker J. (2008) Evidence for a role of early oestrogens in the central processing of sexually relevant olfactory cues in female mice. Eur. J. Neuorsci. 27, 423-431.

Saitoh Y., Hikake T., Hayashi S., Iguchi T. and Sato T. (2010) Involvement of insulin-like growth factor-I for the regulation of prolactin synthesis by estrogen and postnatal proliferation of lactotrophs in the mouse anterior pituitary. Cell Tissue Res. 340, $147-158$.

Shingo T., Gregg C., Enwere E., Fujikawa H., Hassam R., Geary C., Cross J. C. and Weiss S. (2003) Pregnancy-stimulated neurogenesis in the adult female forebrain mediated by prolactin. Science (New York, N.Y.) 299, 117-120.

Sultan S., Mandairon N., Kermen F., Garcia S., Sacquet J. and Didier A. (2010) Learning-dependent neurogenesis in the olfactory bulb determines long-term olfactory memory. FASEB J. 24, 2355-2363.

Tanapat P., Hastings N. B., Reeves A. J. and Gould E. (1999) Estrogen stimulates a transient increase in the number of new neurons in the dentate gyrus of the adult female rat. J. Neurosci. 19, 5792-5801.

Veyrac A. and Bakker J. (2011) Postnatal and adult exposure to estradiol differentially influences adult neurogenesis in the main and accessory olfactory bulb of female mice. FASEB J. 25, 1048-1057.

Veyrac A., Wang G., Baum M. J. and Bakker J. (2011) The main and accessory olfactory systems of female mice are activated differentially by dominant versus subordinate male urinary odors. Brain Res. 1402, 20-29.

Zhao C., Deng W. and Gage F. H. (2008) Mechanisms and functional implications of adult neurogenesis. Cell 132, 645-660. 


\section{Graphical Abstract}

The contents of this page will be used as part of the graphical abstract of html only. It will not be published as part of main article.
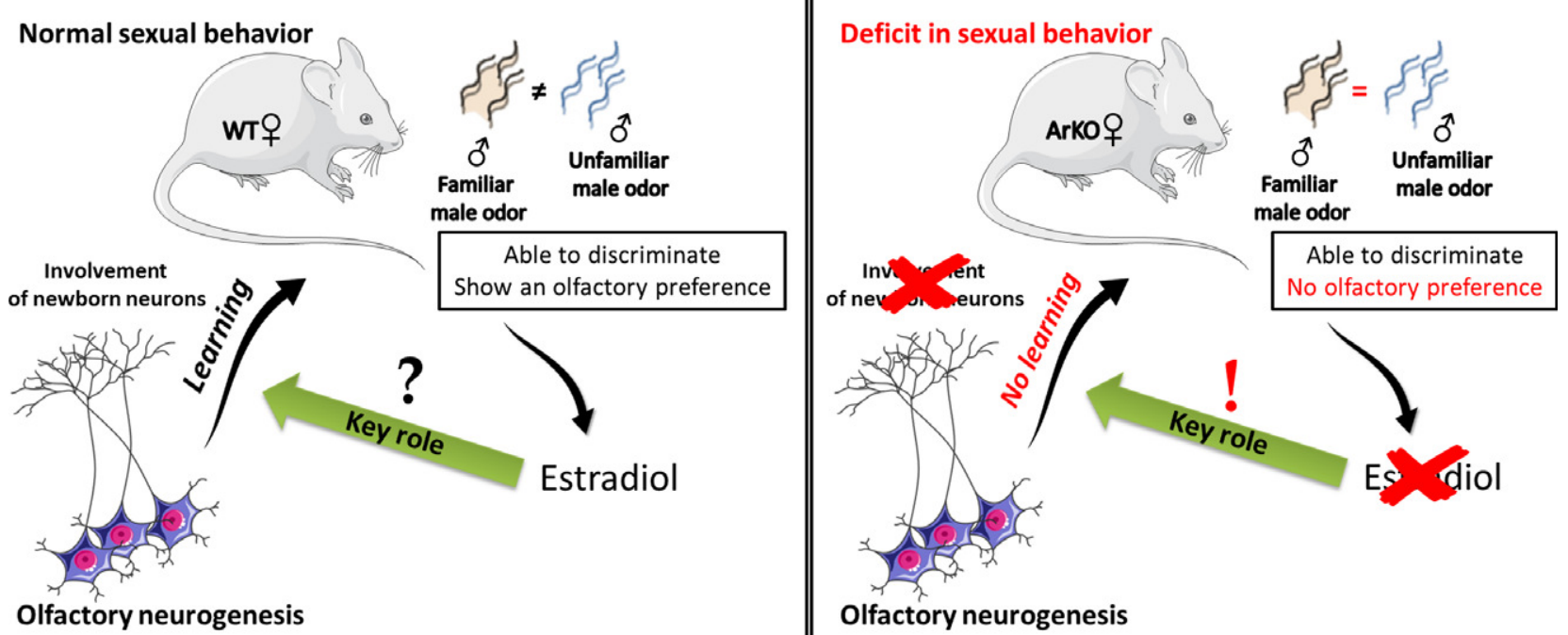

Aromatase knockout mice (ArKO) presented deficits in olfactory preferences without affecting their olfactory discrimination abilities, and showed no functional involvement of newborn neurons in the accessory olfactory bulb (AOB) in response to the odor of a familiar male. These results suggest that estradiol-induced neurogenesis in the female AOB is required for the learning

2 of the male odor. 


\section{Author Query Form}

Journal: $\quad$ JNC

Article: $\quad 13677$

Dear Author,

During the copy-editing of your paper, the following queries arose. Please respond to these by marking up your proofs with the necessary changes/additions. Please write your answers on the query sheet if there is insufficient space on the page proofs. Please write clearly and follow the conventions shown on the attached corrections sheet. If returning the proof by fax do not write too close to the paper's edge. Please remember that illegible mark-ups may delay publication.

Many thanks for your assistance.

\begin{tabular}{|c|c|c|}
\hline Query reference & Query & Remarks \\
\hline 1 & $\begin{array}{l}\text { AUTHOR: Please confirm that given names (red) and } \\
\text { surnames/family names (green) have been identified } \\
\text { correctly. }\end{array}$ & \\
\hline 2 & $\begin{array}{l}\text { AUTHOR: Please check and confirm that the graphical } \\
\text { abstract is fine for publication. }\end{array}$ & \\
\hline 3 & $\begin{array}{l}\text { AUTHOR: Please check if the abbreviations "GCL (granule } \\
\text { cell layer)" and "GrCL (granular cell layer)" are correct? }\end{array}$ & \\
\hline 4 & $\begin{array}{l}\left.\text { AUTHOR: Please note that "( } \mathrm{N}^{\circ} 1 \text { and } \mathrm{N}^{\circ} 2\right) " \text { has been } \\
\text { changed to "(No. } 1 \text { and No. } 2), " \text { is this correct? }\end{array}$ & \\
\hline 5 & AUTHOR: Please supply Table 1 & \\
\hline 6 & $\begin{array}{l}\text { AUTHOR: Figure } 1 \text { is of poor quality. Please check required } \\
\text { artwork specifications at http://authorservices.wiley.com/ } \\
\text { bauthor/illustration.asp }\end{array}$ & \\
\hline 7 & $\begin{array}{l}\text { AUTHOR: Figure } 2 \text { is of poor quality. Please check required } \\
\text { artwork specifications at http://authorservices.wiley.com/ } \\
\text { bauthor/illustration.asp }\end{array}$ & \\
\hline 8 & $\begin{array}{l}\text { AUTHOR: Figure } 3 \text { is of poor quality. Please check required } \\
\text { artwork specifications at http://authorservices.wiley.com/ } \\
\text { bauthor/illustration.asp }\end{array}$ & \\
\hline 9 & $\begin{array}{l}\text { AUTHOR: Figure } 4 \text { is of poor quality. Please check required } \\
\text { artwork specifications at http://authorservices.wiley.com/ } \\
\text { bauthor/illustration.asp }\end{array}$ & \\
\hline 10 & $\begin{array}{l}\text { AUTHOR: Figure } 5 \text { is of poor quality. Please check required } \\
\text { artwork specifications at http://authorservices.wiley.com/ } \\
\text { bauthor/illustration.asp }\end{array}$ & \\
\hline
\end{tabular}

